\title{
SARS-CoV-2 induces transcriptional signatures in human lung epithelial cells that promote lung fibrosis
}

\author{
Jincheng $\mathrm{Xu}^{1 \dagger}{ }^{1 \dagger}$ Xiaoyue $\mathrm{Xu}^{2,3+}{ }^{\text {, Lina Jiang }}{ }^{1}$, Kamal Dua, ${ }^{4,5}$, Philip M. Hansbro, ${ }^{5,6}$ and Gang Liu, ${ }^{5,6^{*}}$ (D)
}

\begin{abstract}
Background: Severe acute respiratory syndrome (SARS)-CoV-2-induced coronavirus disease-2019 (COVID-19) is a pandemic disease that affects $>2.8$ million people worldwide, with numbers increasing dramatically daily. However, there is no specific treatment for COVID-19 and much remains unknown about this disease. Angiotensin-converting enzyme (ACE)2 is a cellular receptor of SARS-CoV-2. It is cleaved by type II transmembrane serine protease (TMPR SS) 2 and disintegrin and metallopeptidase domain (ADAM) 17 to assist viral entry into host cells. Clinically, SARSCoV-2 infection may result in acute lung injury and lung fibrosis, but the underlying mechanisms of COVID-19 induced lung fibrosis are not fully understood.
\end{abstract}

Methods: The networks of ACE2 and its interacting molecules were identified using bioinformatic methods. Their gene and protein expressions were measured in human epithelial cells after $24 \mathrm{~h} \mathrm{SARS-CoV-2}$ infection, or in existing datasets of lung fibrosis patients.

Results: We confirmed the binding of SARS-CoV-2 and ACE2 by bioinformatic analysis. TMPRSS2, ADAM17, tissue inhibitor of metalloproteinase (TIMP)3, angiotensinogen (AGT), transformation growth factor beta (TGFB1), connective tissue growth factor (CTGF), vascular endothelial growth factor (VEGF) A and fibronectin (FN) were interacted with ACE2, and the mRNA and protein of these molecules were expressed in lung epithelial cells. SARSCoV-2 infection increased ACE2, TGFB1, CTGF and FN1 mRNA that were drivers of lung fibrosis. These changes were also found in lung tissues from lung fibrosis patients.

Conclusions: Therefore, SARS-CoV-2 binds with ACE2 and activates fibrosis-related genes and processes to induce lung fibrosis.

Keywords: Coronavirus, SARS-CoV-2, Angiotensin-converting enzyme 2, Lung fibrosis

\footnotetext{
* Correspondence: gang.liu@uts.edu.au

${ }^{\dagger}$ Jincheng $\mathrm{Xu}$ and Xiaoyue Xu contributed equally to this work.

${ }^{5}$ Centre for Inflammation, Centenary Institute, Camperdown, NSW 2050,

Australia

${ }^{6}$ School of Life Science, Faculty of Science, University of Technology Sydney, Ultimo, NSW 2007, Australia

Full list of author information is available at the end of the article
}

(c) The Author(s). 2020 Open Access This article is licensed under a Creative Commons Attribution 4.0 International License, which permits use, sharing, adaptation, distribution and reproduction in any medium or format, as long as you give appropriate credit to the original author(s) and the source, provide a link to the Creative Commons licence, and indicate if changes were made. The images or other third party material in this article are included in the article's Creative Commons licence, unless indicated otherwise in a credit line to the material. If material is not included in the article's Creative Commons licence and your intended use is not permitted by statutory regulation or exceeds the permitted use, you will need to obtain permission directly from the copyright holder. To view a copy of this licence, visit http://creativecommons.org/licenses/by/4.0/ The Creative Commons Public Domain Dedication waiver (http://creativecommons.org/publicdomain/zero/1.0/) applies to the data made available in this article, unless otherwise stated in a credit line to the data. 


\section{Background}

Coronavirus $(\mathrm{CoV})$ is a group of single-stranded RNA viruses and is a pathogen of the human respiratory system. CoV infection results in lethal respiratory diseases, including severe acute respiratory syndrome (SARS), middle east respiratory syndrome (MERS) and coronavirus disease-2019 (COVID-19). SARS induced by SARS-related coronavirus (SARS-CoV) affected 8096 patients from 2002 to 2003 with a fatality rate of $9.6 \%$ worldwide [1]. MERS-related coronavirus (MERS-CoV) affected 2519 cases with a high fatality of $34.4 \%$ [2]. As of 24th May 2020, a new strain of CoV, SARS-CoV-2 induced COVID-19 has leads to over 5.2 million cases in 188 countries, resulting in more than 337,000 deaths, and numbers substantially increase every day [3]. COVID-19 has become a public health emergency of international concern and designated a pandemic by WHO [3]. The lack of deep understanding of SARS$\mathrm{CoV}-2$ is hampering vaccine development.

The most severe sequela of pathogenic coronavirus infection-induced SARS is lung fibrosis that up to $45 \%$ of SARS patients develop lunf fibrosis after 3-6 months, and this potentially sets an important context for COVID-19 [4-7]. Lung fibrosis is characterised by excessive deposition of extracellular matrix (ECM) proteins, such as fibronectin (Fn). This results in impaired lung function and reduced gas exchange. Transforming growth factor beta (TGF- $\beta$ ) associated signalling pathway play important roles in lung fibrosis, but the role of this pathway in COVID-19 is unclear. A recent study shows that COVID-19 patients have a high risk of lung fibrosis [8]. Increasing studies show that COVID-19induced acute respiratory distress syndrome (ARDS) results in diffused alveolar damages in lungs, and the cases of long-term ARDS leading to lung fibrosis are starting to be reported [9-13]. However, the links between SARS-CoV-2 and lung fibrosis remains unclear.

SARS-CoV and SARS-CoV-2 share approximately $76 \%$ amino acid sequence homology that lead to the similarities in their biological properties [14]. The spike (S) protein is a key structural component of $\mathrm{CoV}$ that binds to host cellular receptors that facilitates viral entry into target cells [15]. Angiotensin-converting enzyme 2 (ACE2) has been identified as a receptor of SARS-CoV-2 [4], which is cleaved by type II transmembrane serine protease (TMPRSS2) to augment virus entry into host cells [15]. ACE2 is also cleaved by a disintegrin and metallopeptidase domain (ADAM)17 of the host, which facilitates shedding of ACE2 into the extracellular space to bind with $\mathrm{CoV}$ [16]. However, it remains unclear how SARS-CoV-2 infection induces lung fibrosis.

In this study, we examined SARS-CoV-2 entry into target cells by binding with ACE2 after TMPRSS2 and ADAM17 cleavage. We found that human alveoli epithelial cells are the main target cells of SARS-CoV-2 rather than airway bronchial epithelial cells. SARS-CoV2 infection alters gene expression, including tissue inhibitor of metalloproteinase (TIMP)3, angiotensinogen (AGT), TGFB1, connective tissue growth factor (CTGF), vascular endothelial growth factor (VEGF) A and FN1, and these changes are also observed in lung tissues from patients with lung fibrosis. SARS-CoV-2 infection likely activates TGF- $\beta$ signalling, increases FN expression and results in lung fibrosis.

\section{Materials and methods \\ Predicted SARS-CoV protein and ACE2 binding}

Previous studies showed a conserved evolutionary relationship between SARS-CoV and SARS-CoV-2 [14]. The $\mathrm{S}$ protein of SARS-CoV-2 and its predicted receptor, ACE2 were identified based on a public database using p-hipster as previously described [17].

\section{The interaction network of ACE2 genes and proteins}

Predicted gene/protein interactions were obtained from online databases using bioinformatics analysis. We used GeneMANIA (University of Toronto) to generate an interaction network of $A C E 2$ and related proteins [18]. Previous studies showed that TMPRSS2 cleaves ACE2 [19], and multiple gene queries were chosen in humans for searching the gene network of these two molecules. The predicted genes that interacted with $A C E 2$ and TMPRSS2 were listed using cytoscape analysis (GeneMANIA cytosacpe plugin).

A connective network of ACE2 protein and its functional interactions were obtained using STRING version 11.0 (ELIXIR Infrastructure) as previously described [20]. Briefly, ACE2 and TMPRSS2 were used in main searching list name and organism was Homo sapiens. We selected textmining, experiments, databases and coexpression as active interaction sources. High confidence was used as the interaction score and the disconnected nodes in the network were hidden to simplify the display.

\section{Genotype-tissue expression (GTEx) pilot analysis}

The GTEx project is an RNA-sequencing database of gene expression in different tissues [21]. It links regulatory expression quantitative trait loci (eQTL) variants (gene expression) to tissues. A network of $A C E 2, T M P R$ SS2, ADAM17, TIMP3, AGT, TGFB1, VEGFA, CTGF and $F N 1$ genes across all human tissues were generated using GTEx Portal as previously described [22].

\section{Protein detection in lungs}

Representative images of ACE2, TMPRSS2, ADAM17, AGT, TGFB1, VEGFA, CTGF and FN proteins in human lung tissues were obtained from the Human Protein 
Atlas database as previously described [23]. The Tissue Atlas and Pathology Atlas database (version 19.3) was mined for the expression and localization of these proteins in the lung tissues by immunohistochemistry, and representative images were taken to show the localisation of the target proteins in lung tissues [24].

\section{Single cell analysis of human lung datasets}

We analysed the expressions of ACE2, TMPRSS2, ADAM17, TIMP3, AGT, TGFB1, VEGFA, CTGF and FN1 in different lung cell populations using previously published human single cell RNA-sequencing datasets. All datasets were explored in the UCSC cell browser to identify the cellular sources of those genes in the airways or lung tissues.

In the first dataset [25], human bronchial epithelial cells (HBECs) were obtained from endobronchial lining fluid by invasive bronchoscopy microscampling $(n=4)$, and lung samples $(n=12)$ were obtained by surgical intervention. Endobronchial lining fluid was collected from non-involved segment from the contralateral lungs of patients with lung cancer, and HBECs were isolated and grew in culture media [25]. Lung tissues were obtained from lung cancer patients, and normal lung tissues was distant from the tumour area [25]. These samples were snap-frozen by liquid nitrogen without direct touch and stored at $-80^{\circ} \mathrm{C}$. RNA-sequencing was performed using 10X Genomics Chromium platform of IIIumina HiSeq4000. In the second dataset [26], single cells were isolated from cryobiopsy samples from one idiopathic pulmonary fibrosis (IPF) patient. In the third dataset, single cell samples were obtained from lung biopsies from donors with healthy lungs, but were dead with other diseases or accident $(n=8)$, including stroke (one patient), intracranial haemorrhage (three patients), anoxic brain injury (three patients) and head trauma from gunshot wound (one patient) and patients with pulmonary fibrosis $(n=8)$, including IPF (four patients), interstitial lung diseases (ILD, three patients) and hypersensitivity pneumonitis (one patient) [26].

Cells were clustered using a graph-based shared nearest neighbor clustering approach and graphs were visualised using a t-distributed Stochastic Neighbor Embedding (tSNE) plot to identify the main cellular source of those genes in the airways or lungs.

\section{Gene expressions in human epithelial cells treated with SARS-CoV-2}

The gene expressions of ACE2, TMPRSS2, ADAM17, TIMP3, AGT, TGFB1, VEGFA, CTGF and FN1 were from an existing RNA-sequencing dataset [27] through Gene Expression Omnibus (GEO) database. The data were analyzed using Bioconductor in $\mathrm{R}$ (Bioconductor) as previously described [28-30]. Briefly, in the GSE147507 dataset [27], human adenocarcinoma alveolar basal epithelial
(A549, $\left.1 \times 10^{6}\right)$ cells and HBECs $\left(1 \times 10^{5}\right)$ were infected with SARS-CoV-2 (deposited by the Centre for Disease Control and Prevention and obtained through BEI Resources) or media controls for $24 \mathrm{~h}$ and total RNA was extracted by TRIzol Reagent (ThermoFisher). RNA-seq libraries of polyadenylated RNA were prepared using the TruSeq RNA library Prep Kit V2 (Illumina) and RNA-seq libraries for total ribosomal RNA-depleted RNA were prepared using the TruSeq Stranded Total RNA library Prep Gold (Illumina).

\section{Gene expression in human lung fibrosis datasets}

We analysed the gene expression of ACE2, TMPRSS2, ADAM17, TIMP3, AGT, TGFB1, VEGFA, CTGF and FN1 in lung samples from pre-existing gene microarray datasets.

In GSE2052 dataset [31-33], lung tissues were obtained from healthy controls $(n=11)$ and IPF patients $(n=13)$. DNA was isolated from lung histology for gene array analysis and data was profiled by an Amersham Biosciences Codelink uniset human bioarray.

In the GSE10667 dataset [34-36], lung tissues were from lung healthy controls $(n=15)$, ILD patients with usual interstitial pneumonia (UIP) histopathologic pattern but not IPF (other ILD, $n=23$ ) or IPF patients $(n=8)$. Samples were obtained from surgical remnants of biopsies or lungs explanted from patients with IPF who underwent lung transplant. Control normal lung tissues obtained from the disease-free margins with normal histology of lung cancer resection specimens. Gene expression was profiled by Agilent- 014850 Whole $\mathrm{Hu}$ man Genome Microarray 4x44K G4112F.

The Benjamini-Hochberg method for adjusted $P$ value/false discovery rate (FDR) was used to analyse differences between groups. Statistical significance was set at FDR $<0.05$. Target gene expression was calculated as $\log _{2}$ intensity robust multi-array average signals ( $\log _{2}$ transformed intensity value) [37].

\section{Statistical analysis}

Results are presented as mean \pm standard error of the mean (SEM). Unpaired student $t$-Tests were used to compare two groups in existing dataset analysis. A oneway analysis of variance (ANOVA) with Bonferroni comparisons was used to compare between multiple groups [38]. All statistical analyses were performed using GraphPad Prism Software (San Diego, CA, USA) as previously described [39].

\section{Results}

Network of ACE2 and selected interacting factors in SARA S-CoV-2 infection

We confirmed that the main $\mathrm{S}$ protein of SARS-CoV (grey color) bound to ACE2 protein (red color) using p-hipster analysis (Fig. 1a), which is consistent with previous studies 


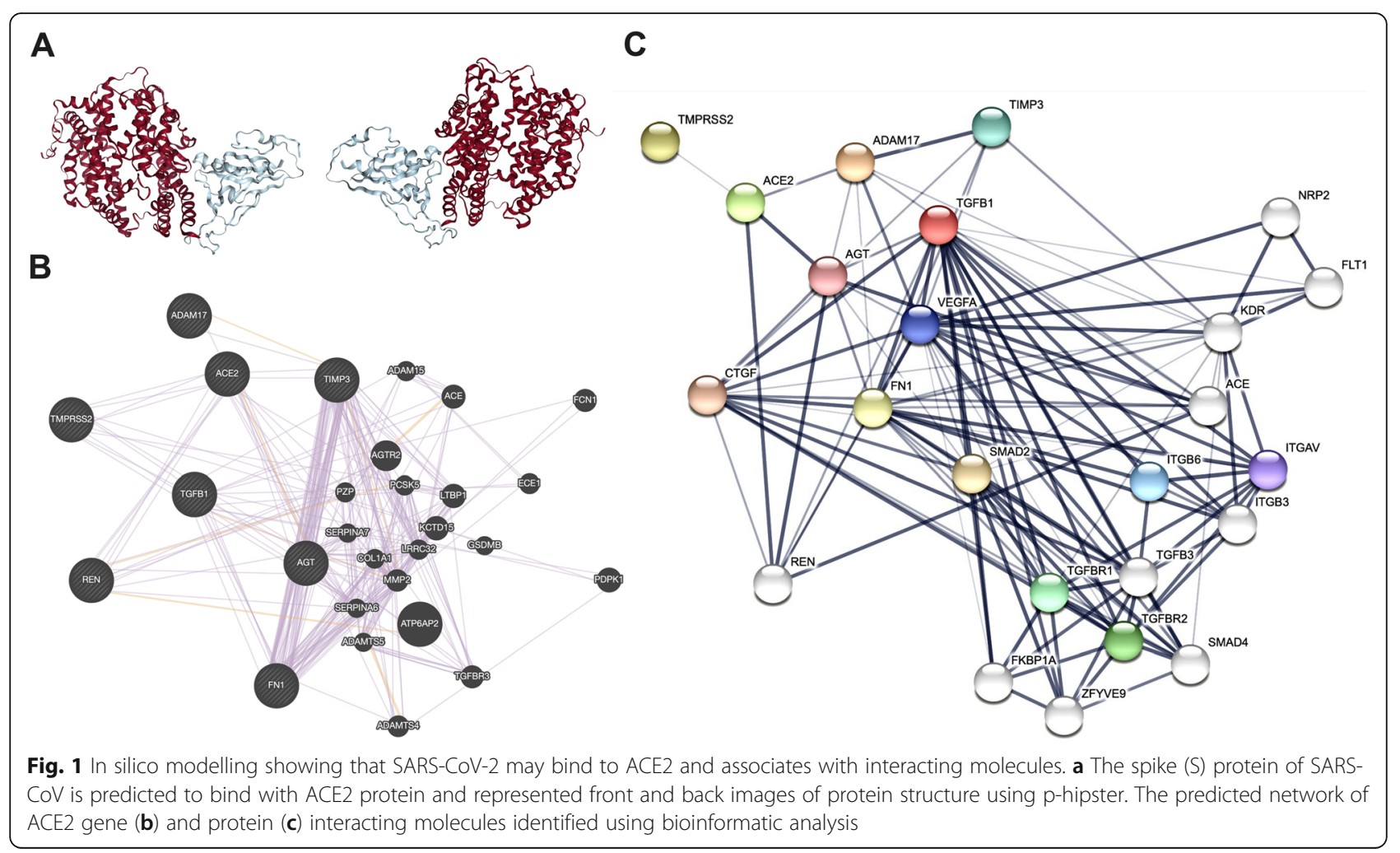

[40]. ADAM17 and TMPRSS2 are the main enzymes that cleave ACE2 and promote SARS-CoV-2 entry into host cells [19]. To understand the process of SARS-CoV-2 binding, we identified the network of $A C E 2$ and its interacting genes using Gene MANIA [18]. TMPRSS2, ADAM17, TIMP3, AGT, TGFB1, FN1 and renin (REN) were indicated to interact with $A C E 2$ (Fig. 1b). We then performed a bioinformatic analysis at the protein level of these molecules to show their protein-protein binding relationship using STRING (Fig. 1c). We found that TMPR SS2, ADAM17, TIMP3, AGT, TGFB1 and FN were the main proteins that interact with ACE2 after binding with SARS-CoV-2. We excluded REN in the following analysis as this molecule was not highlighted by protein interaction analysis.

\section{ACE2 and its interacting proteins were found in lung}

To further investigate the role of ACE2 and its interacting proteins in SARS-CoV-2 infection/COVID-19, the expression of $A C E 2$ gene in different organs were identified using GTEx portal (Fig. 2a). ACE2 mRNA expression in the lung was lower than levels in the small intestine (Fig. 2b). Most of the mRNAs of selected ACE2 interacting molecules were highly expressed in human lungs, including ADAM17, TIMP3, TGFB1, VEGFA, $C T G F$ and FN1. To indicate that the expression of these genes was converted into protein, we identified which proteins are high abundant in the lungs and assessed the cellular sources of their proteins in human lung using a Human Protein Atlas database [23]. All of these proteins were found in lung epithelial cells based on their cellular morphology. While ACE2 and TMPRSS2 proteins occurred at a low level ADAM17, AGT and TGFB1 had a moderate level in normal lung tissues (Fig. 2c). VEGFA, CTGF and FN1 proteins were highly expressed in lung tissues, and TIMP3 was not present in this protein database.

\section{ACE2 and its interacting factors were expressed in lung epithelial cells}

There were two main types of epithelial cells in the lung, airway and alveolar epithelial cells [41]. To further examine the specific cellular source of ACE2 and interacting factors in human airways, cells were collected from human bronchial biopsies and single cell RNAsequencing analysis was performed (Fig. 3a). The mRNA expression of $A C E 2$ and all of the selected interacting factors, including TMPRSS2, ADAM17, TIMP3, AGT, TGFB1, VEGFA, CTGF and FN1 were detectable in bronchial epithelial cells, while TGFB1, VEGFA, CTGF and $F N 1$ were also found in airway fibroblasts (Fig. 3b). We then explored the cellular sources of these molecule in lung tissues, in particular the parenchyma (Fig. 3c). $A C E 2$ and $A G T$ mRNAs were found in type 1 (AT1) and type 2 alveolar epithelial (AT2) cells, but their levels were lower than other selected mRNAs, TMPRSS2, 


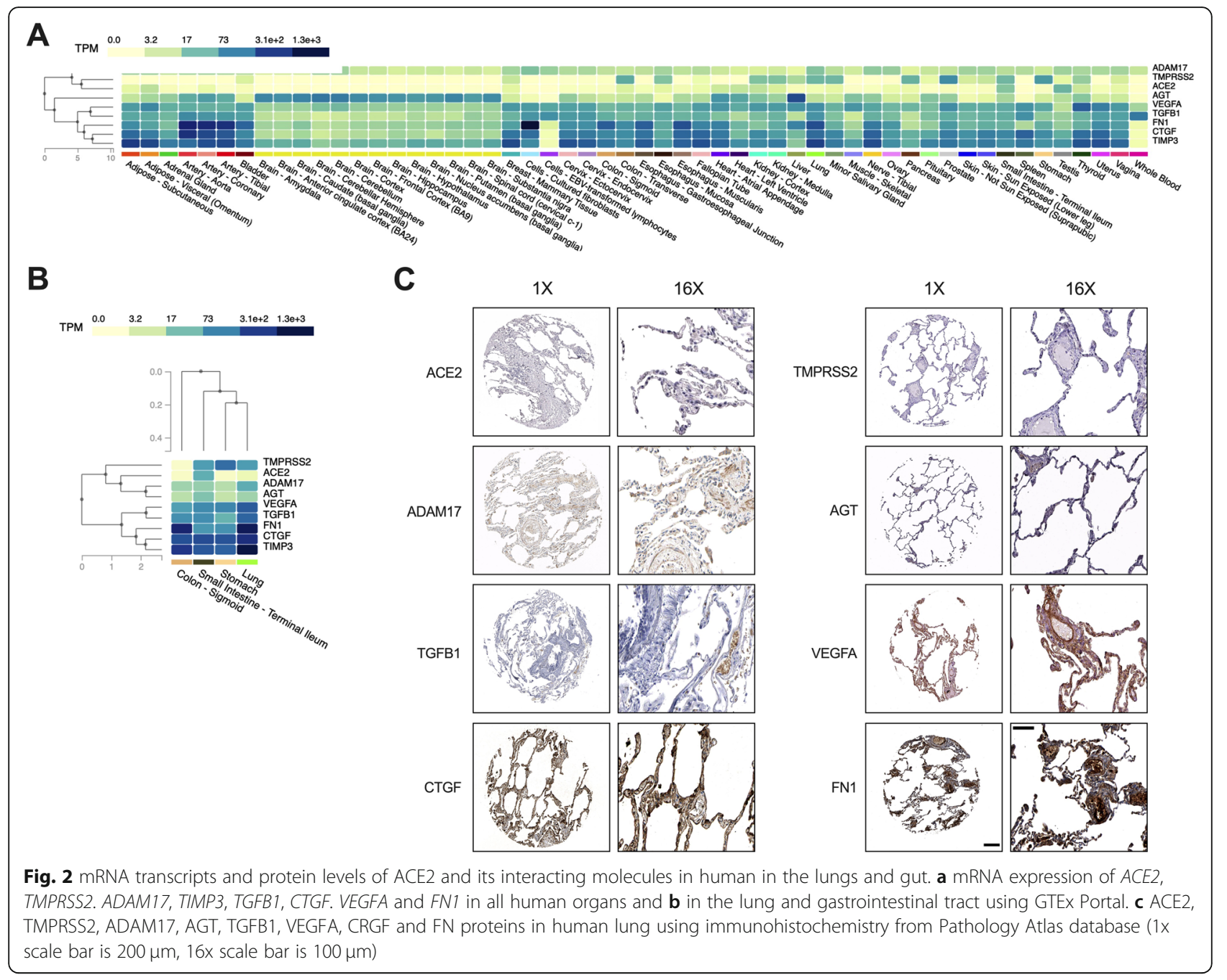

ADAM17, TIMP3, TGFB1, VEGFA, CTGF and FN1 (Fig. 3d).

\section{SARS-CoV-2 infection affects ACE2 and its selected interacting factors in alveolar but not bronchial epithelial cells}

HBECs and alveolar epithelial (A549) cells were inoculated with SARS-CoV-2 for $24 \mathrm{~h}$ and the mRNA expression of $A C E 2$ and selected interacting factors were assessed based on an existing RNA-seq dataset (GSE147507). ACE2 mRNA expression had a nonsignificant trend to increase $(p=0.091)$ in alveolar epithelial cells with SARS-CoV-2 infection compared to sham-infected controls (Fig. 4a). Infection significantly increased the expression of ACE2, TMPRSS2, ADAM17, TGFB1, CTGF, VEGFA and FN1 but resulted in trends towards decreases in TIMP3 $(p=0.083)$ and AGF $(p=0.086)$ in A549 cells compared to control cells (Fig. 4b-i). However, the mRNA expression of $A C E 2$ and interacting factors were not changed in HBECs with infection.
Alveolar epithelial cells are major cellular sources of ACE2 and interacting factors in lung fibrosis

To understand the link between SARS-CoV-2 and lung fibrosis, we identified the cellular source of $A C E 2$ and interacting factors in cryobiopsy samples from one IPF patient using an existing single cell RNA-sequencing dataset (Fig. 5a). The mRNAs of ACE2, TMPRSS2, ADAM17, TIMP3, TGFB1, CTGF. VEGFA and FN1 were found in alveolar epithelial cells (Fig. 5b). To further confirm alveolar epithelial cells were the cellular sources of the interacting factors, we analysed another single cell RNA-sequencing dataset from the lung tissues of eight IPF patients (Fig. 5c). ACE2 mRNA was mainly found in alveolar epithelial cells, but its level was low in lung tissues (Fig. $5 \mathrm{~d}$ ). The mRNAs of $A C E 2$ interacting factors were found in epithelial cells, confirming our previous data (Fig. 2). TMPRSS2 and VEGFA mRNAs were mainly found in all types of epithelial cells, but ADAM17, TGFB1 and FN1 mRNAs were also detected in macrophages and fibroblasts. 


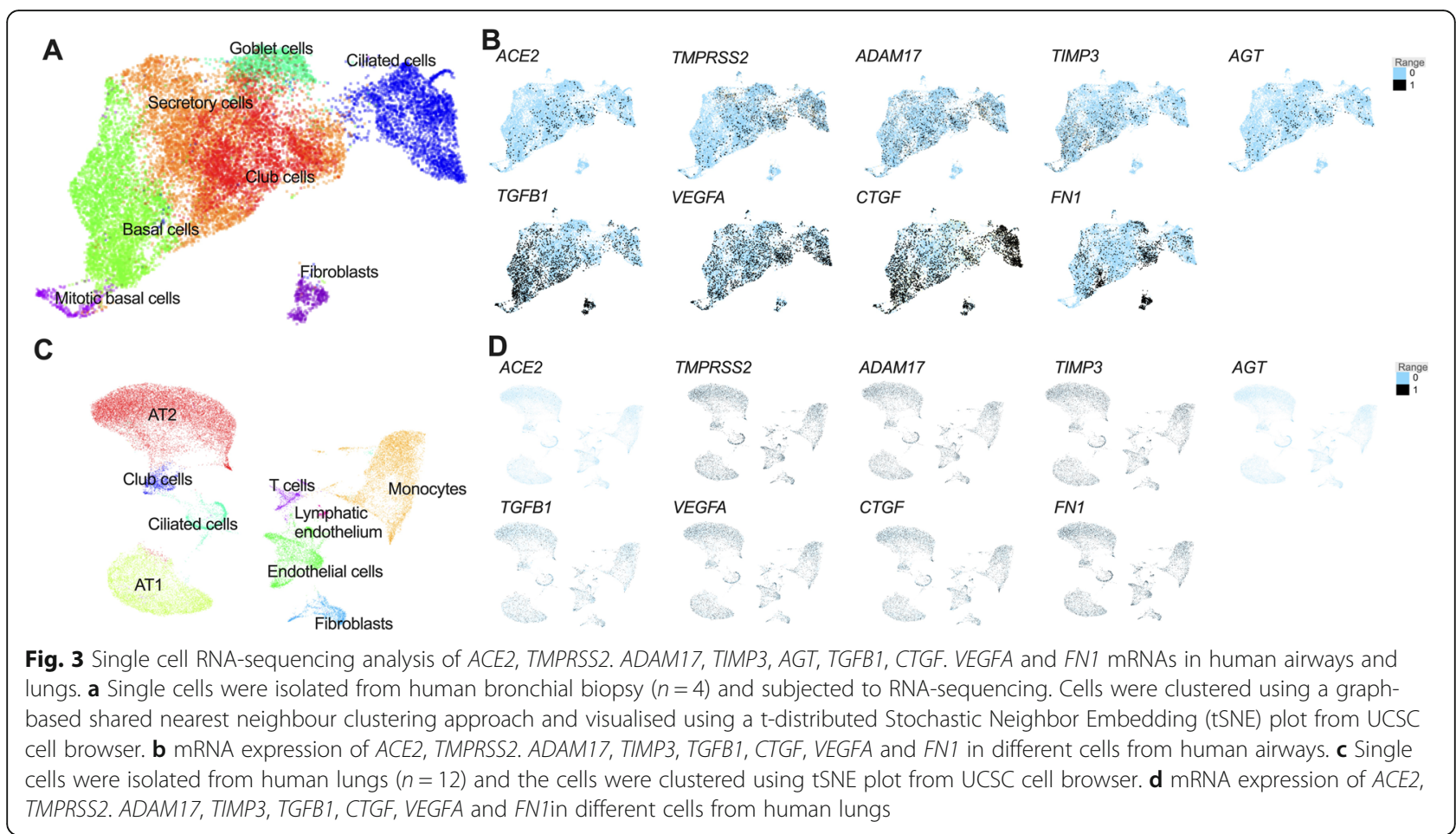

\section{ACE2 and fibrotic related genes were also found in lung} fibrosis patients

To understand how SARS-CoV-2 infection may induce lung fibrosis, we measured the mRNA expression of $A C E 2$ and interaction factors in pre-existing microarray datasets from histological tissues from IPF patients and healthy controls [31-33]. IPF is a severe form of lung fibrosis [42], but it is unclear what causes of this disease. ACE2 mRNA expression was significantly increased in lung tissues from IPF patients compared to controls (Fig. 6a). TMPRSS2 mRNA was not changed (Fig. 6b), but TIMP3 mRNA levels were decreased in IPF patients (Fig. 6c). TGFB1 mRNA expression was not statistical different but there was a trend to an increase in IPF patients (Fig. 6d). Both CTGF and VEGFA mRNAs were decreased but FN1 mRNA was significantly increased in IPF patients (Fig. 6e-g). ADAM17 and $A G T$ mRNAs were not detectable in this dataset.

To further identify possible links between COVID-19 and lung fibrosis, we analysed the mRNA expressions of $A C E 2$ and interaction factors in a different dataset where RNA was isolated from fresh lung tissues from IPF patients and lung healthy controls [34, 35]. We also included a group of other ILD patients with UIP pattern, which is another lung fibrosis disease with known causes compared to IPF [41]. ACE2 mRNA was increased in lung tissues from both IPF and other ILD patients compared to controls (Fig. 7a). TMPRSS2 mRNA was significantly reduced in lung tissues from IPF patients compared to other ILD patients and control (Fig. 7b).
ADAM17 mRNA was not changed between all groups (Fig. 7c), and there was a trend to reduced TIMP3 mRNA $(p=0.084)$ in IPF patients compared to other groups (Fig. 7d). AGF and TGFB1 mRNAs were increased in the patients with both forms of lung fibrosis compared to controls (Fig. 7e and f), but CTGF mRNA was decreased in IPF patients compared to other groups (Fig. 7g). VEGFA mRNA was decreased in other ILD patients compared to other groups (Fig. 7h). FN1 mRNA was increased in lung tissues from IPF patients compared to other groups, was also increased in other ILD patients compared to controls (Fig. 7i).

\section{Discussion}

COVID-19 is a pandemic disease that is induced by SARS-CoV-2. As of 24th May, it has affected more than 5.2 million people across the world causing 337,000 deaths. Studies demonstrate that SARS-CoV-2 infection may result in the similar effects as SARS-CoV due to the similarity of their sequence [14]. One of the major consequences of SARS is that patients develop lung fibrosis as a major sequela. Increasing studies show that COVID-19 patients have lung fibrosis [9-12], however it remains unknown how SARS-CoV-2 infection induces this. ACE2 is a cellular receptor of SARS-CoV-2, and we have confirmed the potential binding relationship of ACE2 and SARS-CoV-2 using bioinformatic analysis in the current study. In addition, we also show that SARSCoV-2 infection associates with increases of fibrosisrelated gene transcription that induces lung fibrosis. 
A

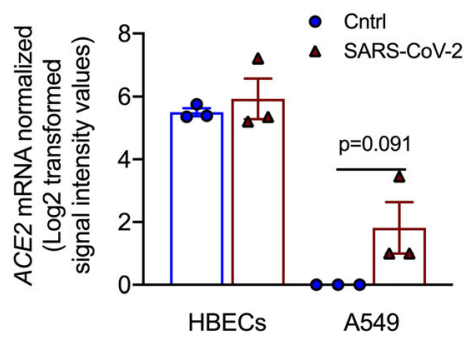

C

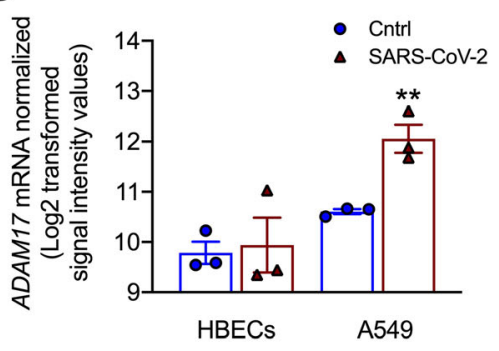

E

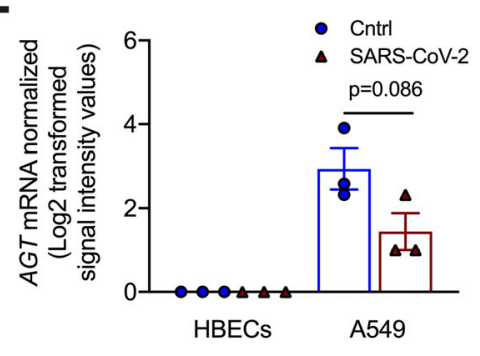

G

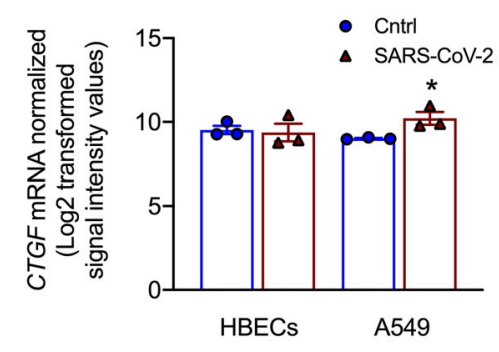

I

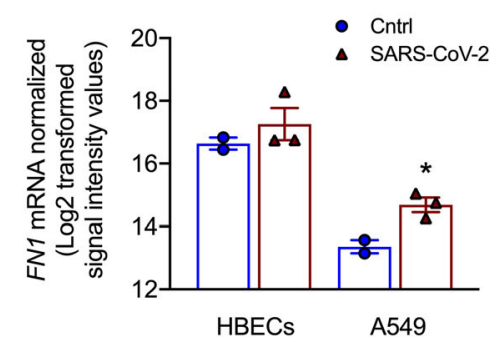

B

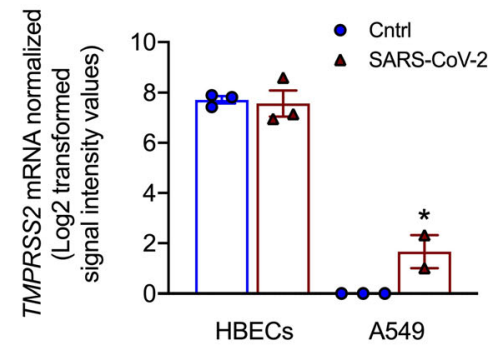

D

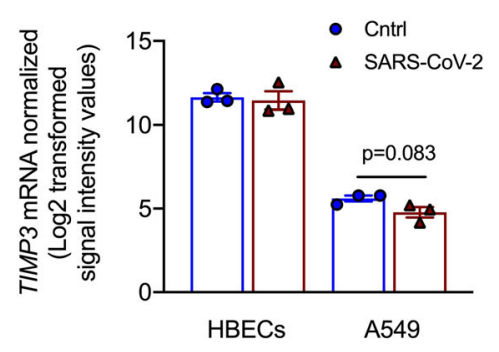

$\mathbf{F}$

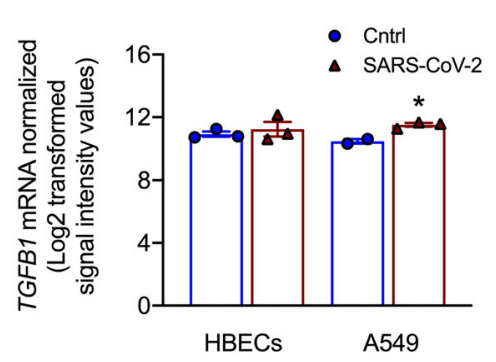

H

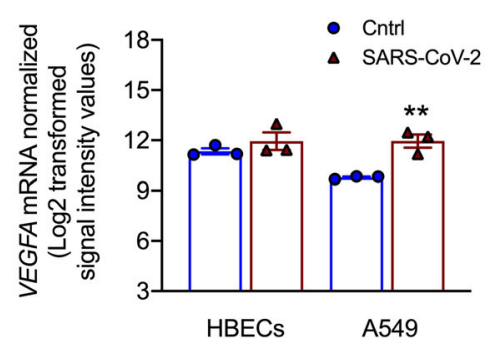

Fig. 4 (See legend on next page.) 
(See figure on previous page.)

Fig. 4 SARS-CoV-2 infection induces Ace2 gene and its interacting factors in human alveolar but not bronchial epithelial cells. Human bronchial epithelial cells (HBEC) and alveolar epithelial (A549) cells were infected with SARS-CoV-2 for $24 \mathrm{~h}$, and control cells received medium only. The mRNA expression of ACE2 (a), TMPRSS2 (b), ADAM17 (c), TIMP3 (d), AGF (e), TGFB1 (f), CTGF (g), VEGFA (h) and FN1 (i) in HBECs and alveolar epithelia cells. $n=2-3,{ }^{*} P<0.05,{ }^{*} P<0.01$ compared to control cells

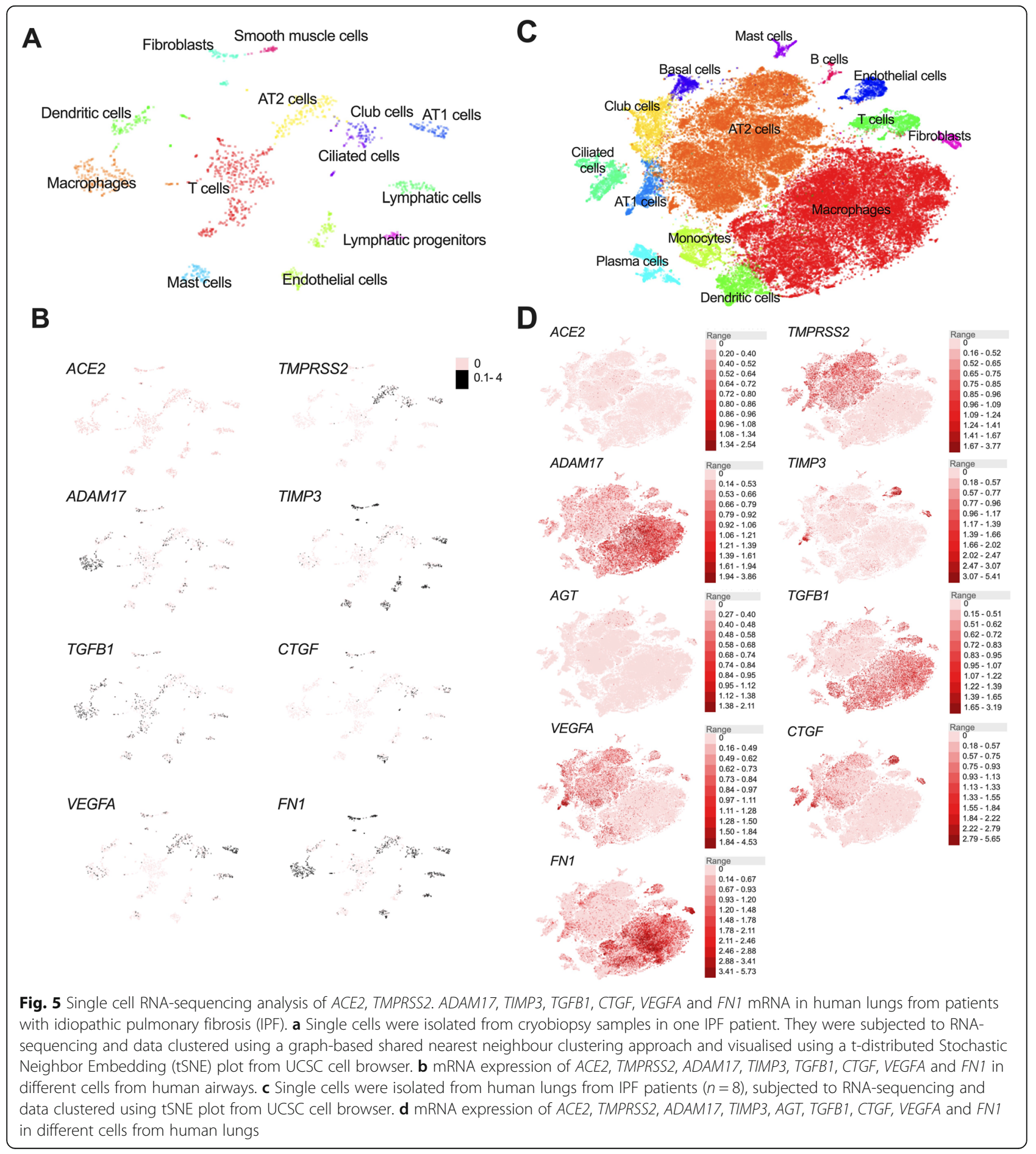




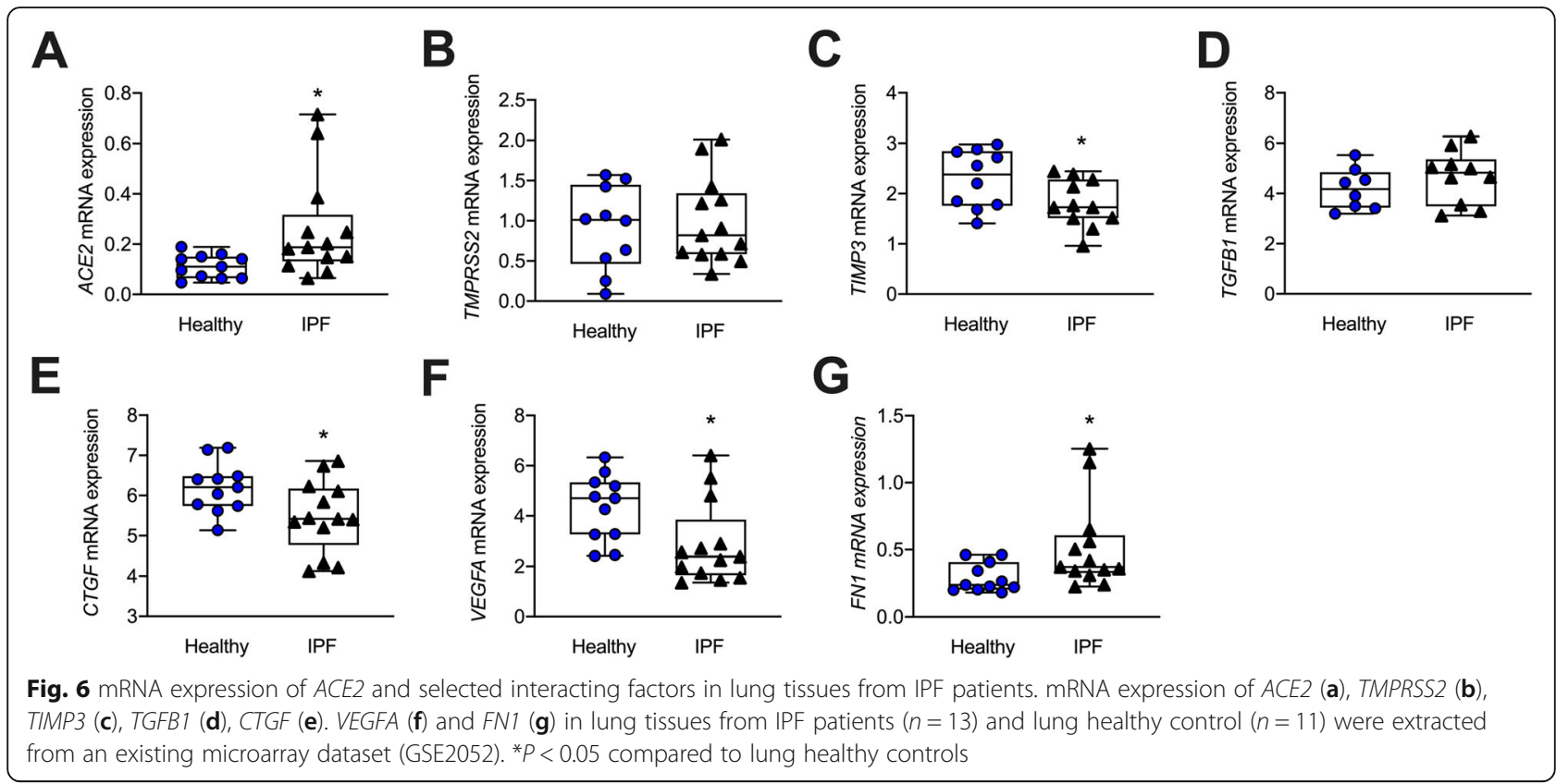

The baseline level of ACE2 mRNA expression is very low in lungs compared to other organs. It is increased in alveolar epithelial cells after SARS-CoV-2 infection, indicating a positive correlation of ACE2 and SARS-CoV-2 infection. We have found that ACE2 mRNA expression is mainly found in gastrointestinal (GI) tract and the small intestine has the highest level of $A C E 2$ levels compared to other organs in this study. Diarrhea is one of major symptoms of COVID-19 and high numbers of ACE2 positive small intestine cells occur in COVID-19 patients [43]. This indicates that SARS-CoV-2 also may also affect the GI tract through the ACE2 receptor. It remains unclear how SARS-CoV-2 reaches the GI tract in
COVID-19 patients. Possible routes are through infected food [44] or transmission from the lung to the GI tract via the lung-gut axis [45-47]. Live SARS-CoV-2 was detected in stool samples from patients who had respiratory issues but not diarrhea [48], suggesting SARS-CoV2 infection occurs through lung-gut axis. On the other hand, a recent study showed that three children had positive SARS-CoV-2 tests in their stools, but negative results in their throat swab samples, indicating the virus enters these patients via oral infection [49]. The infection may also transmit from the gut to the lung [50], causing a secondary infection [39]. Respiratory and digestive systems are the two major pathways that SARS-

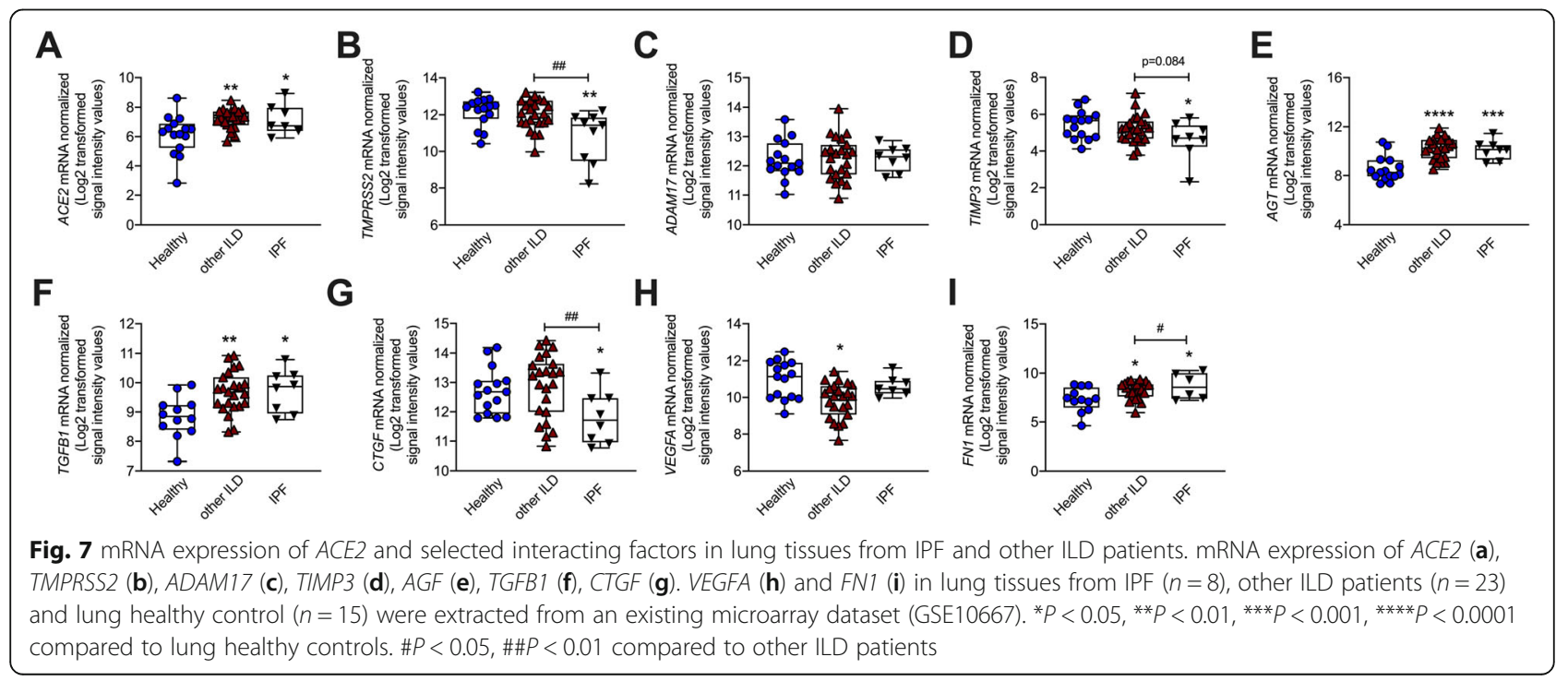


CoV-2 enters the body. Thus, it has been recommended that routine stool testing should be performed in potential COVID-19 patients even after viral RNA clearance in their respiratory system [51].

There is a high chance that COVID-19 patients potentially develop lung fibrosis, but how infection leads to fibrosis remains unclear. TGF- $\beta$ is a cytokine that promotes the development of fibrosis. Active TGF- $\beta$ regulates the level of ECM proteins, which are major factors involved in tissue remodelling and fibrosis [42]. CTGF is another cytokine involved in the remodelling process and the induction of lung fibrosis [52]. We find that TGFB1 and CTGF mRNA transcripts are significantly increased in alveolar epithelial cells after SARS-CoV-2 infection. FN is a major ECM protein that has critical roles in tissue remodelling and fibrosis [53]. Our previous studies showed that increased FN deposition is linked with lung fibrosis [42], and we show in the current study that increased FN1 mRNA transcripts are present in lung tissues from lung fibrosis patients. Inhibiting a main functional domain of the FN1 gene inhibits fibrosis features in an in vivo model of lung fibrosis [54]. In this study, we found that SARS-CoV-2 infection induced FN1 gene expression in alveolar epithelial cells, indicating the early induction of fibrotic processes and how the virus may be driving this.

ACE2 is cleaved by ADAM17 and/or TMPRSS2 before SARS-CoV-2 binds, and the cleavage of the receptor facilitates virus entry into host cells [16]. These events may be self-promoting and the mRNA expression of TMPRSS 2 and ADAM17 are increased in alveolar epithelial cells after SARS-CoV-2 infection. The enzyme activity of ADAM17 is inhibited and regulated by TIMP3 [55], but SARS-CoV-2 reduces TIMP3 mRNA expression in alveolar epithelial cells, that likely promotes greater ADAM17 activity in COVID-19 patients. TMPR SS2 and ADAM17 may compete for ACE2 cleavage, and processing by TMPRSS 2 promotes more virus entry than that of ADAM17 [19]. Thus, increased activity of these enzymes after SARS-CoV-2 infection may contribute lung fibrosis but this needs to be proven clinical and experimental studies.

Bronchial epithelial cells mount the initial response SARS-CoV-2, however we show that ACE2 mRNA levels are not changed in HBECs after infection compared to sham-infected controls. HBECs mount little response to infection compared to alveolar epithelial cells, and induces pneumonia, suggesting that SARS-CoV-2 infection directly induces disorders in parenchyma, including lung fibrosis. HBECs may respond to a higher inoculum of SARS-CoV-2 or in a shorter timeframe that require further experiment.

Abnormal tissue remodelling results in lung fibrosis and this process is currently irreversible [56]. Pulmonary fibrosis patients have only an average $2-3$ years survival of the after they have been confirmed with this lethal disease [57]. Many lung fibrosis patients do not have major or previous symptoms, but have late stage lung fibrosis upon diagnosis. Thus, the most responsive treatment time may be missed. Early diagnosis is now considered critical but is a major challenge. Since COVID-19 patients may develop lung fibrosis [9-12], early prevention and intervention may significantly reduce the number of lung fibrosis patients-induced by SARS-CoV-2 infection.

\section{Conclusion}

Taken together, we have shown links between SARSCoV-2 binding with ACE2 and TGF- $\beta$ and CTGF. This process may induce ECM products, such as FN in alveolar epithelial cells, and may result in lung fibrosis in COVID-19 patients. Thus, a routine analysis and early prevention, diagnosis and treatment of lung fibrosis may be beneficial for COVID-19 patients.

\section{Abbreviations}

ACE: Angiotensin-converting enzyme; ADAM: A disintegrin and metallopeptidase domain; AGT: Angiotensinogen; AT1: Type 1 alveolar epithelial; AT2: Type 2 alveolar epithelial; CoV: Coronavirus (CoV); COVID19: Coronavirus disease-2019; CTGF: Connective tissue growth factor; FN: Fibronectin; GEO: Gene expression omnibus; eQTL: Expression quantitative trait loci; Gl: Gastrointestinal; HBECs: Human bronchial epithelial cells; ILD: Interstitial lung disease; IPF: Idiopathic pulmonary fibrosis; MERS: Middle east respiratory syndrome; REN: Renin; SARS: Severe acute respiratory syndrome; SARS-CoV: SARS-related coronavirus;

TGFB1: Transformation growth factor beta; TIMP: Tissue inhibitor of metalloproteinase; TMPRSS: Type II transmembrane serine protease; tSNE: tdistributed Stochastic Neighbor Embedding; UIP: Usual interstitial pneumonia; VEGF: Vascular endothelial growth factor

\section{Authors' contributions}

J.X and G.L participated in research design. J.X, X.X and G.L performed bioinformatic and statistical analysis. J.X, L.J and G.L interpreted results. X.X, K.D, P.M.H and G.L drafted and revised the manuscript. J.X, X.X, L.J, K.D, P.M.H and G.L read and approved the manuscript.

\section{Funding}

This work was supported by Thoracic Society of Australia and New Zealand (G.L). P.M.H is funded by a Fellowship and grants from the National Health and Medical Research Council (NHMRC) of Australia (1175134).

\section{Availability of data and materials}

The datasets generated and analysed during the current study are available in the Gene expression omnibus [https://www.ncbi.nlm.nih.gov/geo/] and UCSC bell browser [https://cells.ucsc.edu/\#] repositories.

\section{Ethics approval and consent to participate}

The human sample collections and the experiments in pre-existing datasets (GSE147507, GSE2052 and GSE10667) were approved by the Ethical Committee of original studies. The dataset analysis was approved by Ethics Committee of Bengbu Medical College.

\section{Consent for publication}

Not applicable.

Competing interests

The authors declare that they have no competing interests. 


\section{Author details}

${ }^{1}$ School of Stomatology, Bengbu Medical College, Bengbu 2033, Anhui, China. ${ }^{2}$ School of Public Health and Community Medicine, Faculty of Medicine, University of New South Wales, Kensington 233000, NSW, Australia. ${ }^{3}$ Faculty of Health, University of Technology Sydney, Ultimo, NSW 2007, Australia. ${ }^{4}$ Discipline of Pharmacy, Graduate School of Health, University of Technology Sydney, Ultimo, NSW 2007, Australia. ${ }^{5}$ Centre for Inflammation, Centenary Institute, Camperdown, NSW 2050, Australia. ${ }^{6}$ School of Life Science, Faculty of Science, University of Technology Sydney, Ultimo, NSW 2007, Australia.

\section{Received: 28 April 2020 Accepted: 6 July 2020} Published online: 14 July 2020

\section{References}

1. WHO: Summary of probable SARS cases with onset of illness from 1 November 2002 to 31 July 2003. 2020.

2. WHO: Epidemic and pandemic-prone diseases, MERS situation update, January 2020. 2020.

3. WHO: Coronavirus disease 2019 (COVID-19) Situation Report - 125. 2020

4. Xie L, Liu Y, Xiao Y, Tian Q, Fan B, Zhao H, Chen W. Follow-up study on pulmonary function and lung radiographic changes in rehabilitating severe acute respiratory syndrome patients after discharge. Chest. 2005;127:211924.

5. Hui DS, Joynt GM, Wong KT, Gomersall CD, Li TS, Antonio G, Ko FW, Chan MC, Chan DP, Tong MW, et al. Impact of severe acute respiratory syndrome (SARS) on pulmonary function, functional capacity and quality of life in a cohort of survivors. Thorax. 2005;60:401-9.

6. Venkataraman T, Frieman MB. The role of epidermal growth factor receptor (EGFR) signaling in SARS coronavirus-induced pulmonary fibrosis. Antivir Res. 2017;143:142-50.

7. Zhang P, Li J, Liu H, Han N, Ju J, Kou Y, Chen L, Jiang M, Pan F, Zheng Y, et al. Long-term bone and lung consequences associated with hospitalacquired severe acute respiratory syndrome: a 15-year follow-up from a prospective cohort study. Bone Res. 2020;8:8.

8. Sun P, Qie S, Liu Z, Ren J, Li K, Xi J. Clinical characteristics of hospitalized patients with SARS-CoV-2 infection: a single arm meta-analysis. J Med Virol. 2020;92:612-7.

9. Shi H, Han X, Jiang N, Cao Y, Alwalid O, Gu J, Fan Y, Zheng C. Radiological findings from 81 patients with COVID-19 pneumonia in Wuhan, China: a descriptive study. Lancet Infect Dis. 2020;20:425-34.

10. Pan Y, Guan H, Zhou S, Wang Y, Li Q, Zhu T, Hu Q, Xia L. Initial CT findings and temporal changes in patients with the novel coronavirus pneumonia (2019-nCoV): a study of 63 patients in Wuhan, China. Eur Radiol. 2020;30: 3306-9.

11. Ye Z, Zhang Y, Wang Y, Huang Z, Song B. Chest CT manifestations of new coronavirus disease 2019 (COVID-19): a pictorial review. Eur Radiol. 2020;30: 4381-9.

12. Conti $P$, Gallenga $C$, Tetè $G$, Caraffa A, Ronconi $G$, Younes A, Toniato E, Ross R, Kritas S. How to reduce the likelihood of coronavirus-19 (CoV-19 or SARSCoV-2) infection and lung inflammation mediated by IL-1. J Biol Regul Homeost Agents. 2020;34. https://doi.org/10.23812/Editorial-Conti-2.

13. Zhang W. Imaging changes of severe COVID-19 pneumonia in advanced stage. Intensive Care Med. 2020;46:841-3.

14. Munster VJ, Koopmans M, van Doremalen N, van Riel D, de Wit E. A novel coronavirus emerging in China - key questions for impact assessment. $\mathrm{N}$ Engl J Med. 2020;382:692-4.

15. Hoffmann M, Kleine-Weber H, Schroeder S, Krüger N, Herrler T, Erichsen S, Schiergens TS, Herrler G, Wu N-H, Nitsche A, et al. SARS-CoV-2 cell entry depends on ACE2 and TMPRSS2 and is blocked by a clinically proven protease inhibitor. Cell. 2020;181:271-80.

16. Haga S, Yamamoto N, Nakai-Murakami C, Osawa Y, Tokunaga K, Sata T, Yamamoto N, Sasazuki T, Ishizaka Y. Modulation of TNF-alpha-converting enzyme by the spike protein of SARS-COV and ACE2 induces TNF-alpha production and facilitates viral entry. Proc Natl Acad Sci U S A. 2008;105: 7809-14.

17. Lasso G, Mayer SV, Winkelmann ER, Chu T, Elliot O, Patino-Galindo JA, Park K, Rabadan R, Honig B, Shapira SD. A structure-informed atlas of humanvirus interactions. Cell. 2019;178:1526-41.

18. Franz M, Rodriguez H, Lopes C, Zuberi K, Montojo J, Bader GD, Morris Q. GeneMANIA update 2018. Nucleic Acids Res. 2018;46:W60-4.
19. Heurich A, Hofmann-Winkler H, Gierer S, Liepold T, Jahn O, Pohlmann S. TMPRSS2 and ADAM17 cleave ACE2 differentially and only proteolysis by TMPRSS2 augments entry driven by the severe acute respiratory syndrome coronavirus spike protein. J Virol. 2014;88:1293-307.

20. Szklarczyk D, Gable AL, Lyon D, Junge A, Wyder S, Huerta-Cepas J, Simonovic M, Doncheva NT, Morris JH, Bork P, et al. STRING v11: proteinprotein association networks with increased coverage, supporting functional discovery in genome-wide experimental datasets. Nucleic Acids Res. 2019; 47:D607-13

21. Consortium GT. The genotype-tissue expression (GTEx) project. Nat Genet. 2013;45:580-5.

22. Consortium GT: Human genomics. The genotype-tissue expression (GTEx) pilot analysis: multitissue gene regulation in humans. Science. 2015;348:648-60.

23. Uhlen M, Fagerberg L, Hallstrom BM, Lindskog C, Oksvold P, Mardinoglu A, Sivertsson A, Kampf C, Sjostedt E, Asplund A, et al. roteomics. Tissue-based map of the human proteome. Science. 2015;347:1260419.

24. Uhlen M, Zhang C, Lee S, Sjostedt E, Fagerberg L, Bidkhori G, Benfeitas R, Arif M, Liu Z, Edfors F, et al. A pathology atlas of the human cancer transcriptome. Science. 2017;357:eaan2507.

25. Lukassen S, Chua RL, Trefzer T, Kahn NC, Schneider MA, Muley T, Winter $\mathrm{H}$, Meister M, Veith C, Boots AW, et al. SARS-CoV-2 receptor ACE2 and TMPR SS2 are primarily expressed in bronchial transient secretory cells. EMBO J. 2020;39:e105114.

26. Reyfman PA, Walter JM, Joshi N, Anekalla KR, McQuattie-Pimentel AC, Chiu S, Fernandez R, Akbarpour M, Chen Cl, Ren Z, et al. Single-cell Transcriptomic analysis of human lung provides insights into the pathobiology of pulmonary fibrosis. Am J Respir Crit Care Med. 2019;199: 1517-36.

27. Blanco-Melo D, Nilsson-Payant B, Liu W-C, Uhl S, Hoagland D, Moeller R, Jordan T, Oishi K, Panis M, Sachs D, et al. Imbalanced host response to SARS-CoV-2 drives development of COVID-19. Cell, 2020;181:1036-45.

28. Li J, Xu X, Jiang Y, Hansbro NG, Hansbro PM, Xu J, Liu G. Elastin is a key factor of tumor development in colorectal cancer. BMC Cancer. 2020;20:217.

29. Bhattacharya S, Srisuma S, Demeo DL, Shapiro SD, Bueno R, Silverman EK, Reilly JJ, Mariani TJ. Molecular biomarkers for quantitative and discrete COPD phenotypes. Am J Respir Cell Mol Biol. 2009;40:359-67.

30. Christenson SA, van den Berge M, Faiz A, Inkamp K, Bhakta N, Bonser LR, Zlock LT, Barjaktarevic IZ, Barr RG, Bleecker ER, et al. An airway epithelial IL$17 \mathrm{~A}$ response signature identifies a steroid-unresponsive COPD patient subgroup. J Clin Invest. 2019;129:169-81.

31. Wang XM, Zhang Y, Kim HP, Zhou Z, Feghali-Bostwick CA, Liu F, Ifedigbo E, Xu X, Oury TD, Kaminski N, Choi AM. Caveolin-1: a critical regulator of lung fibrosis in idiopathic pulmonary fibrosis. J Exp Med. 2006;203:2895-906.

32. Pardo A, Gibson K, Cisneros J, Richards TJ, Yang Y, Becerril C, Yousem S, Herrera I, Ruiz V, Selman M, Kaminski N. Up-regulation and profibrotic role of osteopontin in human idiopathic pulmonary fibrosis. PLoS Med. 2005;2:e251.

33. Englert JM, Hanford LE, Kaminski N, Tobolewski JM, Tan RJ, Fattman CL, Ramsgaard L, Richards TJ, Loutaev I, Nawroth PP, et al. A role for the receptor for advanced glycation end products in idiopathic pulmonary fibrosis. Am J Pathol. 2008;172:583-91.

34. Konishi K, Gibson KF, Lindell KO, Richards TJ, Zhang Y, Dhir R, Bisceglia M, Gilbert S, Yousem SA, Song JW, et al. Gene expression profiles of acute exacerbations of idiopathic pulmonary fibrosis. Am J Respir Crit Care Med. 2009;180:167-75.

35. Yamashita CM, Dolgonos L, Zemans RL, Young SK, Robertson J, Briones N, Suzuki T, Campbell MN, Gauldie J, Radisky DC, et al. Matrix metalloproteinase 3 is a mediator of pulmonary fibrosis. Am J Pathol. 2011;179:1733-45.

36. Rosas IO, Richards TJ, Konishi K, Zhang Y, Gibson K, Lokshin AE, Lindell KO, Cisneros J, Macdonald SD, Pardo A, et al. MMP1 and MMP7 as potential peripheral blood biomarkers in idiopathic pulmonary fibrosis. PLoS Med. 2008:5:e93.

37. Kaiko GE, Chen F, Lai CW, Chiang IL, Perrigoue J, Stojmirovic A, Li K, Muegge BD, Jain $U$, VanDussen $\mathrm{KL}$, et al. PAl-1 augments mucosal damage in colitis. Sci Transl Med. 2019;11:eaat0852.

38. Xu X, Ling M, Inglis SC, Hickman L, Parker D. Eating and healthy ageing: a longitudinal study on the association between food consumption, memory loss and its comorbidities. Int J Public Health. 2020. https://doi.org/10.1007/ s00038-020-01337-y.

39. Liu G, Baird AW, Parsons MJ, Fan K, Skerrett-Byrne DA, Nair PM, Makanyengo S, Chen J, Neal R, Goggins BJ, et al. Platelet activating factor receptor acts to limit colitis-induced liver inflammation. FASEB J. 2020;34:7718-32. 
40. Wan Y, Shang J, Graham R, Baric RS, Li F. Receptor recognition by the novel coronavirus from Wuhan: an analysis based on decade-long structural studies of SARS coronavirus. J Virol. 2020;94:e00127-20.

41. Hiemstra PS, Tetley TD, Janes SM. Airway and alveolar epithelial cells in culture. Eur Respir J. 2019;54:1900742.

42. Liu G, Cooley MA, Jarnicki AG, Borghui T, Nair PM, Tjin G, Hsu AC, Haw TJ, Fricker $\mathrm{M}$, Harrison $\mathrm{CL}$, et al: Fibulin-1c regulates transforming growth factor$\beta$ activation in pulmonary tissue fibrosis. JCI Insight. 2019;4:e124529.

43. Barker $\mathrm{H}$, Parkkila S. Bioinformatic characterization of angiotensin-converting enzyme 2, the entry receptor for SARS-CoV-2. bioRxiv. 2020. https://doi.org/ 10.1101/2020.04.13.038752.

44. Jalava K. First respiratory transmitted food borne outbreak? Int J Hyg Environ Health. 2020;226:113490.

45. Budden KF, Gellatly SL, Wood DL, Cooper MA, Morrison M, Hugenholtz P, Hansbro PM. Emerging pathogenic links between microbiota and the gut-lung axis. Nat Rev Microbiol. 2017;15:55.

46. Hansbro PM, Hamilton MJ, Fricker M, Gellatly SL, Jarnicki AG, Zheng D, Frei SM, Wong GW, Hamadi S, Zhou S, et al. Importance of mast cell Prss31/ transmembrane tryptase/tryptase-gamma in lung function and experimental chronic obstructive pulmonary disease and colitis. J Biol Chem. 2014;289:18214-27.

47. Dhar D, Mohanty A. Gut microbiota and Covid-19- possible link and implications. Virus Res. 2020;285:198018.

48. Wang W, Xu Y, Gao R, Lu R, Han K, Wu G, Tan W. Detection of SARS-CoV-2 in different types of clinical specimens. JAMA. 2020;323:1843-4.

49. Zhang T, Cui X, Zhao X, Wang J, Zheng J, Zheng G, Guo W, Cai C, He S, Xu Y. Detectable SARS-CoV-2 viral RNA in feces of three children during recovery period of COVID-19 pneumonia. J Med Virol. 2020;92:909-14.

50. Liu G, Mateer SW, Hsu A, Goggins BJ, Tay H, Mathe A, Fan K, Neal R, Bruce J, Burns $G$. Platelet activating factor receptor regulates colitis-induced pulmonary inflammation through the NLRP3 inflammasome. Mucosal Immunol. 2019;12:862-73.

51. Wu Y, Guo C, Tang L, Hong Z, Zhou J, Dong X, Yin H, Xiao Q, Tang Y, Qu X, et al. Prolonged presence of SARS-CoV-2 viral RNA in faecal samples. Lancet Gastroenterol Hepatol. 2020;5:434-5.

52. Allen JT, Spiteri MA. Growth factors in idiopathic pulmonary fibrosis: relative roles. Respir Res. 2002;3:13.

53. Liu G, Cooley MA, Nair PM, Donovan C, Hsu AC, Jarnicki AG, Haw TJ Hansbro NG, Ge Q, Brown AC, et al. Airway remodelling and inflammation in asthma are dependent on the extracellular matrix protein fibulin-1c. J Pathol. 2017;243:510-23.

54. Muro AF, Moretti FA, Moore BB, Yan M, Atrasz RG, Wilke CA, Flaherty KR, Martinez FJ, Tsui JL, Sheppard D, et al. An essential role for fibronectin extra type III domain a in pulmonary fibrosis. Am J Respir Crit Care Med. 2008;177: 638-45.

55. Casagrande V, Mauriello A, Bischetti S, Mavilio M, Federici M, Menghini R. Hepatocyte specific TIMP3 expression prevents diet dependent fatty liver disease and hepatocellular carcinoma. Sci Rep. 2017;7:6747.

56. Liu G, Cooley MA, Jarnicki AG, Hsu AC, Nair PM, Haw TJ, Fricker M, Gellatly SL, Kim RY, Inman MD, et al. Fibulin-1 regulates the pathogenesis of tissue remodeling in respiratory diseases. JCI Insight. 2016;1:e86380.

57. Raghu G, Collard HR, Egan JJ, Martinez FJ, Behr J, Brown KK, Colby TV, Cordier J-F, Flaherty KR, Lasky JA. An official ATS/ERS/JRS/ALAT statement: idiopathic pulmonary fibrosis: evidence-based guidelines for diagnosis and management. Am J Respir Crit Care Med. 2011;183:788-824.

\section{Publisher's Note}

Springer Nature remains neutral with regard to jurisdictional claims in published maps and institutional affiliations.

Ready to submit your research? Choose BMC and benefit from:

- fast, convenient online submission

- thorough peer review by experienced researchers in your field

- rapid publication on acceptance

- support for research data, including large and complex data types

- gold Open Access which fosters wider collaboration and increased citations

- maximum visibility for your research: over $100 \mathrm{M}$ website views per year

At BMC, research is always in progress.

Learn more biomedcentral.com/submissions 